\section{SM Preventive \\ Medicine and \\ Public Health}

\section{Article Information}

Received date: Aug 20, 2018

Accepted date: Sep 10, 2018

Published date: Sep 14, 2018

\section{*Corresponding author}

Ana Pinto de Oliveira, Arnaldo Sampaio Public Health, Arco Ribeirinho Health Centre Assembly, Portugal, Tel: +351 21206 9810; Email: ana.pinto. oliveira@arslvt.min-saude.pt

Distributed under Creative Commons CC-BY 4.0

Keywords Surveillance; Sexually Transmitted Infections; Notifiable Diseases; Underreporting

Abbreviations ACES AR: Arco Ribeirinho Health Center Assembly; ARS: Regional Health Administration; AS: Health Authority; CDC: Centers for Disease Control and Prevention; DGS: Directorate-General for Health; HCV: Hepatitis C Virus; HIV: Human Immunodeficiency Vírus; ICPC: International Classification of Primary Care; INS: National Serological Survey; MNCD: Mandatory Notifiable Communicable Disease; SD: Mean; SIARS: Information Health System Administration; SINAVE: National System of Epidemiological Surveillance; SPSS: Statistics Package for Social Sciences; STIs: Sexually Transmitted Infections; USA: United States of America; USPAS: ArnaldoSampaio Public Health Unit; WHO: World Health Organization

Article DOI 10.36876/smpmph.1024

\section{OPEN ACCESS}

\section{ISSN: 2576-4004}

\section{Prevalence of Sexually Transmitted Infections and Their Underreporting in a Health Region of Portugal, From 2015 To 2017}

\author{
Ana Pinto de Oliveira ${ }^{*}$, Catarina Oliveira and Lina Guarda \\ Arnaldo Sampaio Public Health, Arco Ribeirinho Health Centre Assembly, Portugal
}

\section{Abstract}

Background: Although public health surveillance system data are widely used to describe the epidemiology of communicable disease, occurrence of sexually transmitted infections may be misrepresented by underreporting. Reporting of cases of notifiable sexually transmitted infections is important in the planning and evaluation of disease prevention and control programs, in the assurance of appropriate medical therapy, and in the detection of common-source outbreaks.

This study was carried out to examine the relationship between case-reporting of notifiable sexually transmitted infections in the Notifiable Diseases Surveillance System and the medical diagnosis recorded in Health Management Information System, of Regional Health Administration of Lisbon and the Tagus Valley

Methods: Data on reported cases of notifiable sexually transmitted infections, in the geographical area covered by Arco Ribeirinho Health Centre Assembly, from January 2015 to December 2017, were obtained from the Notifiable Diseases Surveillance System at Arnaldo Sampaio Public Health. Data regard medical diagnosis in the same geographical area and time period were achieved in Health Management Information System, of Regional Health Administration of Lisbon and the Tagus Valley.

Results: From 2015 to 2017, 167 cases of sexually transmitted infections were notified in Arco Ribeirinho Health Centre Assembly. Twenty-eight percent of cases were syphilis, $25.7 \%$ of cases were gonorrhea, $18.5 \%$ of cases were VIH and $27.7 \%$ of cases were notified with at least one other STI. Most of reported cases were observed in Alto Seixalinho (27.5\%), Baixa da Banheira (19.1\%), and Montijo-Afonsoeiro (16.1\%) counties.

Of 487 STIs medical diagnosis, 92 were reported to the National System Epidemiological Surveillance, corresponding to $65.7 \%$ of underreporting. The majority of these under-reported cases were for VHB and VHC $(92.2 \%)$ and $\mathrm{VIH}(80.9 \%)$

Conclusion: This study underlines the need to increase the percentage of STIs notified to the Health Authority.

\section{Introduction}

Sexually Transmitted Infections (STIs) are now the commonest group of notifiable infectious diseases in most countries, particularly in the age group of 15 to 50 years and in infants [1]. Their control is important considering the high incidence of acute infections, complications and sequelae, their socioeconomic impact, and their role in increasing transmission of the Human Immunodeficiency Virus (HIV) [2].

The increased incidence of STIs is a relevant problem in Public Health, with a high socio-economic weight, due to the significant morbidity and mortality that they cause in young individuals, as well as the harmful consequences that can have on health maternal and child health. The World Health Organization (WHO) estimates the number of new cases of STIs per year worldwide by 250 million [3]. The Centers for Disease Control and Prevention (CDC) estimates that the annual incidence of STIs in the United States of America (USA) is 19 million cases, with adolescents and young adults (15-24 years old) accounting for about half of Human papillomavirus (18\%), Chlamydia trachomatis (4-7\%), Trichomonas vaginalis (3\%), Herpes simplex type 2 (2\%), and Neisseria gonorrhoeae $(0.5 \%)$ [4]. In Portugal, the results of the National Serological Survey 2015-2016 (INS), showed a prevalence of $2.7 \%$ for Chlamydia trachomatis, which is in agreement with the european prevalence estimates for the age group evaluated in this study (18 to 35 years). While seroprevalence for Treponema pallidum was $2.4 \%$, showing higher values at the more advanced ages, which could be explain by the high incidence of syphilis in Portugal in the last century [5]. For HIV and Hepatitis C Virus (HCV) infection, prevalence's of $0.1 \%$ and $0.3 \%$, respectively, were determined [5]. The calculated values will presumably correspond to the prevalence of undiagnosed infections in the resident population in Portugal, since the criteria applied in the selection of the INS participants excluded individuals with an immunodeficiency disease and with chronic liver disease. 
Information about the epidemiology of STIs is obtained from data on STIs cases reported to public health disease surveillance systems. Health surveillance is essential for effective impact assessment, monitoring and control of diseases and risks to health, including STIs, and is necessary for an efficient public health practice capable of effectively protecting and promoting the health of populations [6]. Epidemiological surveillance defined by Lawson (2006) as the systematic and continuous collection, analysis and interpretation of health data for the planning, implementation and evaluation of Public Health practices, accompanied by the timely dissemination of this data to decision makers, with the ultimate goal of its application in prevention and control [7]. In Portugal, epidemiological surveillance is direct essentially at communicable diseases. The Mandatory Notifiable Communicable Diseases (MNCD) system has been established since 1949 in Law 2036 of 9 August, according to which "every clinician (from the public or private system) who diagnosed or suspected a case shall report it within 48 hours" to the Health Authority (AS). It carries out the epidemiological inquiry, implements the epidemiological control plan and sends it to the Regional Health Administration (ARS) and the Directorate-General for Health (DGS). The list of notifiable communicable diseases currently in force is regulated by Ordinances No. 1071/98 of December 31 and No. 258/2006 of 16 March [8,9]. In Portugal, notifiable STIs includeChlamydia trachomatis, Treponema pallidum, Neisseria gonorrhoeae, Hepatitis B, Hepatitis C and HIV.

By 2014, formal notification required the completion of a predefined paper form common to all diseases (Model 1536 - Mandatory Declaration of Communicable Diseases), followed by mailing it to the Health Authority. In July 2014, mandatory notification was initiate by electronic means, through the National System of Epidemiological Surveillance (SINAVE), regulated by Order No. 5855/2014 and No. 5681-A/2014, which permits the dematerialization of mandatory reporting of communicable diseases $[10,11]$. SINAVE provides for national and real-time networking and advocates involving clinicians, public health services, laboratories, Health Authorities and other entities in the public, private and social sectors [12]. The system is based on clinical notifications. Health professionals, especially primary health care providers, are responsible not only for secondary prevention but particularly for primary prevention. In this context, the specialist of General and Family Medicine can be active in health education. The modification of risk behaviors will have a positive impact on the transmission of STIs, preventing the complications of the infection and reducing its impact on society. On the other hand, the appropriate treatment of the infected partners is determinant to prevent the recurrent infections and to interrupt the cycle of transmission of the disease.

Data obtained through surveillance and reporting systems are generally considered underestimated, conditioning uncertainty when the true impact and incidence of the disease or factor in surveillance. Since these data is use in the prioritization of intervention and decision-making in public health, it is important to recognize, quantify and understand the underreporting and the underlying reasons, in order to find strategies to overcome and minimize their influence on the perception of the real impact of the disease or factor in surveillance. In the context presented, the purpose of this study is to describe data of STIs in the geographical area of the Arco Ribeirinho Health Center Assembly (ACES AR), in the period 20152017. The relationship between case-reporting of notifiable STIs and the medical diagnosis, from the same geographical area and time period shall be assessed through the confrontation between provided data by Information Health System Administration (SIARS) and data in SINAVE.

\section{Material and Methods}

An observational, descriptive-retrospective, quantitative study was performed [13]. Data collection occurred in the last quarter of 2017, at the ArnaldoSampaio Public Health Unit (USPAS), of ACES AR. The study's database consisted of all records of STIs cases reported by the healthcare units of the Barreiro, Moita, Montijo, and Alcoche te municipalities to the Health Authority of ACES AR, between January 2015 and December 2017 through the SINAVE. SINAVE defines a probably case of STI as an individual with clinically compatible signs and symptoms and an epidemiologic link to a confirmed case and a confirmed case of STI as laboratory-confirmed case. Notification data collected was the compared with medical diagnosis data at the SIARS to calculate underreporting. Medical diagnosis were coded according to International Classification of Primary Care (ICPC):X92 (Chlamydia infection), Y70 and X70 (Syphilis), Y71 and X71 (gonorrhoeae), D72 (VHB, VHC) and B90 (HIV).Data were analysed using descriptive statistics using Statistics Package for Social Sciences ${ }^{\circledR} 23.0$ (SPSS, Inc., USA) for Windows.

\section{Results}

A total of 167 cases of STIs were reported to the Authority Health from 2015 through 2017. The number of reported cases increased by 66.6\%, from 45 cases in 2015 to 75 cases in 2017. During 2015-2017, the mean (SD) annual STIs case count was 56 cases (range, 46-75). The annual incidence of notified VHB, VHC and Chlamydia cases has been stable, with a mean of 2; 7 and 5 cases reported respectively, per year during 3 years (2015-2017). There was an increase of reported cases of syphilis from 12 cases in 2015 to 17 cases in 2017, of VIH from 6 cases in 2015 to 15 cases in 2017 and of cases of gonorrhea from 11 cases in 2015 to 26 cases in 2017.Mean age-specific incidence rates for the 2015-2017 period generally increased with increasing age group, between 0-10 to 31-40 year old age group. From 2015 through 2017, 43 cases of STIs were reported in patients aged between 3140year old. Persons aged $<65$ years comprised $95.8 \%(n=138)$ of total cases in 2015-2017.

Males comprised $53.2 \%(n=89)$ of the 167 case patients. Rates in males exceeded those in females for all age groups and years. The gap between male and female STIs reported cases steadily widened in adults as the age group increased. The male reported cases exceeded the female cases by $62 \%$ in the $21-30$ and $31-40$ year old age group.

During 2015 through 2017, STIs cases were reported in almost all countys from the Barreiro, Moita, Montijo and Alcochete municipalities. The Barreiro municipality reported the largest percentage of cases $(43.7 \%)$, followed by the Moita (28.1\%), the Montijo (19.7\%), and the Alcochete (8.9\%). Most reported cases (69\%) were concentrated in 3 countys: Alto Seixalinho (27.5\%), Baixa Banheira (19.1\%), and Montijo-Afonsoeiro (16.1\%) (Figure 1).

Ninety-two of the 167 STIs cases were reportedby clinicians from healthcare units from AR HCA, with a mean (SD) annual case count of 31 cases (range, 24-44), during the period 2015 to 2017. In this time, $51.7 \%$ of the notified cases were syphilis infections (25\%), VIH infections (23.9\%) and ghonorrhoeae infections (22.8\%), whereas 


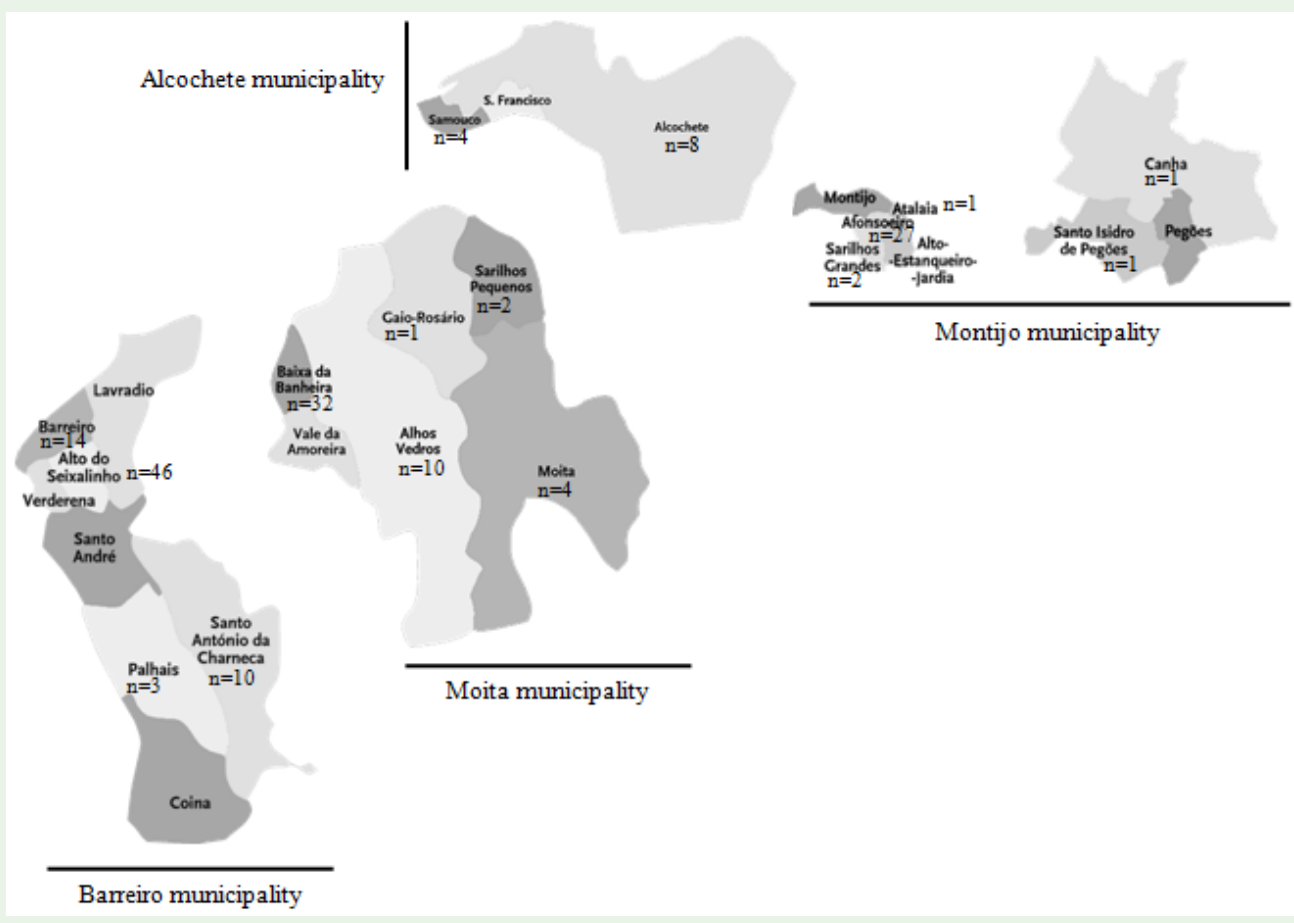

Figure 1: Total number of reported STIs cases by counties, notified by the clinicians from healthcare units of Arco Ribeirinho Health Centre Assembly, from 2015 to 2017.

only $25.9 \%$ of the cases notified were VHC infections (18.4\%), VHB infections (6.65\%) and chlamydia infections (1.08\%).

The 21-30 year old age group had the highest incidence of STIs. The male: female ratio of STIs reported cases were $1: 1$ by 2015 , then increased to 2:1by 2016, and has increased to over 3:1 in 2017. Most STIs cases occurred in the county of Alto of Seixalinho in the municipality of Barreiro.
Only in cases where there is more medical diagnosis than notifications can under-reporting are demonstrated. This occurred in out of notifiable STIs and amounted to an additional $65.7 \%$ of notifications (or 320 cases) which were 'missed' due to clinician under-reporting. The majority of these under-reported cases were for VHB and VHC (92.2\%) and VIH (80.9\%) (Figure 2).

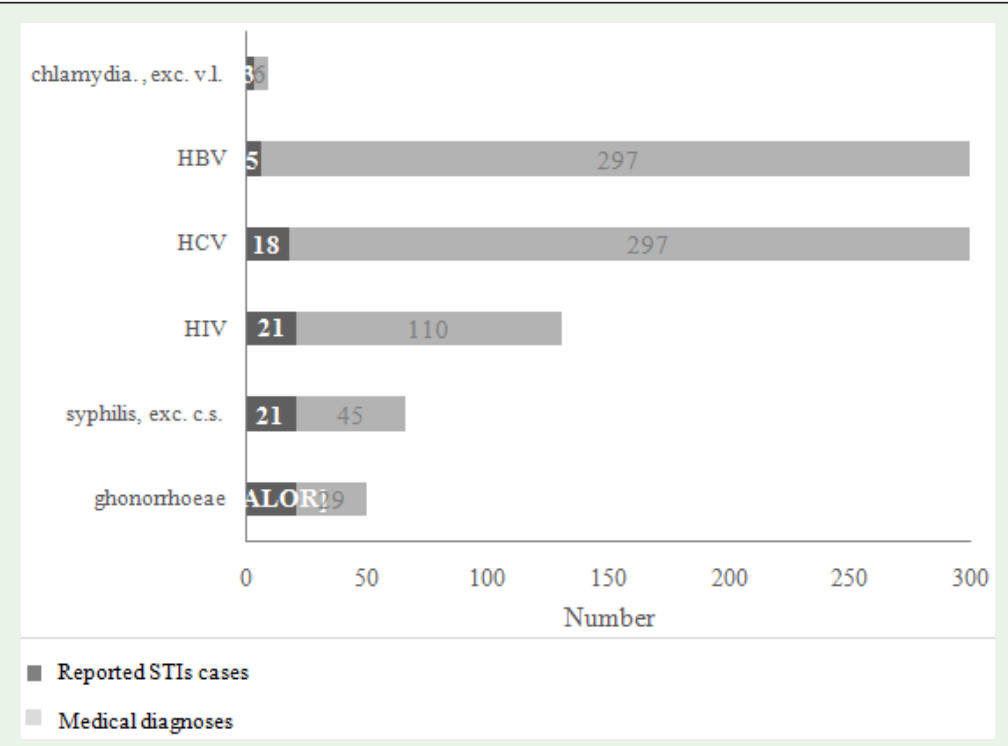

Figure 2: Total number of medical diagnosis and reported STIs cases, by infection, notified by the clinicians from healthcare units of Arco Ribeirinho Health Centre Assembly, from 2015 to 2017.

Citation: de Oliveira AP, Oliveira C and Guarda L. Prevalence of Sexually Transmitted Infections and Their Underreporting in a Health Region of Portugal, From 2015 To 2017. SM Prev Med Public Health. 2018; 2(3): 1024.

https://dx.doi.org/10.36876/smpmph.1024 


\section{Discussion}

An increase in the number of STIs cases and their underreporting in the SINAVE is a problem to overcome in Portugal. Our study demonstrates an increase in reported numbers of STIs cases, between 2015 and 2017, in a health region of Portugal, the ACES AR The overall male/female ratio of STIs cases reported by the clinicians is 2 to 1 , which can be explained by the fact that women often do not show symptoms of STIs. When symptoms develop, they can be confused with other diseases that are not transmitted through sexual contact. Unfortunately, the diseases can still be transmitted to a sex partner even though there are no symptoms.

Over the period from 2015 to 2017, the number of reported VIH, ghonorrhoeae and syphilis cases has increased by $60 \%, 57.6 \%$ and $41.6 \%$, respectively. But VHB, VHC and Chlamydia notifications remained relatively stable. The background for the rise in STIs is probably complex and can notbe explained by any single factor [14].The increases in STIs incidence highlight the need for systems that effectively monitor STI trends and distribution in a timely and efficient manner, in order to inform public health action [15]. The purpose of reporting of STIs is to ensure that persons who are infected will be quickly diagnosed and appropriately treated to control the spread of infection and also so that partners are notified, tested and appropriately treated.

The notifications of STIs have not increased in all regions, but mainly in the Alto Seixalinho (27.5\%), Baixa Banheira (19.1\%), and Montijo-Afonsoeiro (16.1\%) counties.

A possible explanation for this fact could be given by the socioeconomic indicators that describe these counties as those with the largest resident population, the highest unemployment rate, the greater incidence of early school leaving and the larger number of deaths [16].

A substantial under reporting of STIs incidence and burden in the ACES AR is found in the study, by present surveillance mechanisms.

A study conducted in drug-using Female sex workers (FSWs) in Amsterdam reported 34\% underreporting of STI [17] and a study with sexually active adolescents recruited from clinics in the United States found underreporting of STI to be $21 \%-47 \%$ [18]. A 2002 American review, that measured healthcare provider compliance with TB, HIV and STIs reporting, found it to be $79 \%$, and compliance of $49 \%$ when dealing with other diseases [19]. Our study confirms a lower level of reported compliance (34.3\%) than for STIs in the American review. It is therefore crucial to intervene with the professionals who diagnose communicable diseases, in order to increase the percentage of STIs notified to the Health Authority.

Clinicians need to understand their reporting responsibilities as well as the reporting system used by their institution. Health care employers should actively promote the importance of notifiable infectious disease reporting to their clinicians, with the aim of enhancing participation and strengthening the relationships among medical institutions, clinicians, and the public health community.

Further research is required to explain the recent increases in STIs and the under reporting occurrence. Routine collection and dissemination to researchers of more-comprehensive patient risk factor, laboratory diagnostic testing, and other epidemiologic information by national surveillance systems would aid these efforts.

This study has highlighted the extent of under-reporting of notifiable STIs, in a health region in Portugal, which is a cause for concern from a surveillance point of view. If this under-reporting is similar in other regional health, then it would appear that the epidemiology of notifiable STIs is incomplete both regionally and nationally. This under-reporting negatively impacts on the effectiveness of the notification process as a 'real-time' surveillance tool and an early warning system for outbreaks.

\section{Conclusion}

National surveillance of sexually transmitted infections relies on mandatory case reporting, a system that produces data that is often incomplete. These issues result in missed opportunities to identify and respond to trends in disease as well as limited ability to guide STI control. This study underlines the need to increase the percentage of STIs notified to the Health Authority to follow trends in reported cases and to make it possible to direct intervention efforts and prevention campaigns to core groups and risk populations.

\section{References}

1. Weinstock H, Berman S, Cates W Jr. Sexually transmitted diseases among American youth: incidence and prevalence estimates 2000. Perspect Sex Reprod Health. 2004; 36: 6-10.

2. De Schryver A, Meheus A. Epidemiology of sexually transmitted diseases: the global picture. Bulletin of the World Health Organization. 1990; 68: 639654.

3. World Health Organization. Global Health Sector Strategy on Sexually Transmitted Infections 2016-2021: Implementation Framework for the African Region. Geneve: World Health Organization. 2017.

4. Center for Disease and Prevention Control. Sexually Transmitted Disease Surveillance 2016. USA: Center for Disease and Prevention Control. 2017.

5. Instituto Nacional de Saúde Doutor Ricardo Jorge. Inquérito Serológico Nacional (ISN) 2015-2016. Lisboa: Instituto Nacional de Saúde Doutor Ricardo Jorge. 2017

6. Declich S, Carter AO. Public health surveillance: historical origins, methods and evaluation. Bull World Health Organ. 1994; 72: 285-304.

7. Lawson A. Statistical Methods for Spatial epidemiology 2nd Ed Wiley, New York. 2006.

8. Diário da República n. ${ }^{\circ}$ 301/1998, Série I-B de 1998-12-31. Portaria n. ${ }^{\circ}$ $1071 / 98$.

9. Diário da República n. ${ }^{\circ}$ 52/2006, Série I-B de 2006-03-14. Portaria n. ${ }^{\circ}$ $258 / 2006$

10. Diário da República n. ${ }^{\circ} 85 / 2014$, Série I-B de 2014-05-05. Despacho n. ${ }^{\circ}$ $5855 / 2014$

11. Diário da República n- ${ }^{\circ} 82 / 2014$, Série I-B de 2014-04-29.Despacho n. ${ }^{\circ}$ $5681 / 2014$

12. Direção de Serviço de Informação e Análise, Divisão de Epidemiologia e Vigilância. Doenças de Declaração Obrigatória, 2013-2016 Volume II Regiões. Lisboa: Direção Geral da Saúde. 2017.

13. Fronteira I: Observational Studies in the Era of Evidence Based Medicine: Short Review on their Relevance, Taxonomy and Designs. Acta Médica Portuguesa. 2013; 26: 161-170.

14. Morin S, Vernon K, Harcourt J, Steward W, Volk J, Riess T, et al. Why HIV infections have increased among men who have sex with men and what to do about it: findings from California focus groups. AIDS Behav. 2003: 353-362. 
15. Lowndes C, Fenton K, ESSTI (European Surveillance of STIs) Network. Surveillance systems for STIs in the European Union: facing a changing epidemiology. Sexually Transmitted Infections. 2004; 80: 264-271.

16. Statistics Portugal. Statistical Yearbook of Portugal (SYB)-2016. Lisboa: Statistics Portugal (INE). 2017.

17. Fennema J, van Ameijden E, Coutinho R, van den Hoek J. Validity of selfreported sexually transmitted diseases in a cohort of drug-using prostitutes in Amsterdam: Trends from 1986 to 1992. Int J Epidemiol. 1995: 1034-1041.
18. Niccolai L, Kershaw T, Lewis J, Cicchetti D, Ethier K, Ickovics J. Data collection for sexually transmitted disease diagnoses: A comparison of selfreport, medical record reviews, and state health department reports. Ann Epidemiol. 2005: 236-242.

19. Doyle T, Glynn M, Groseclose S. Completeness of notifiable infectious disease reporting in the United States: an analytical literature review. American Journal of Epidemiology. 2002; 155: 866-874 